\title{
Mercados de dois lados
}

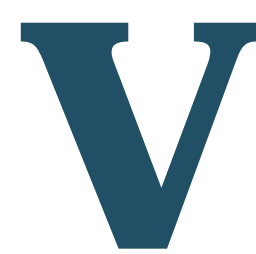

ocê sabe quais princípios econômicos explicam seu cartão de crédito ou débito? As concepções tradicionais de planejamento e implementação de estratégias mercadológicas já não são suficientes para lidar com diversos mercados importantes. N esses mercados todas as premissas fundamentais são alteradas pela necessidade de atender simultaneamente dois ou mais segmentos distintos, mas interdependentes. 0 artigo analisa uma nova abordagem econômica que procura entender esses mercados.

por Ricardo F. Paixão CEAMP-USP, Marcelo C. R. Deschamps D'Alvarenga BACEN* e José Augusto G. da Silveira USP

Diz a literatura de marketing que, para um produto ser bem-sucedido, ele necessita atender algumas condições específicas. 0 sucesso deve basear-se, de um lado, no planejamento dos três " $C s$ " - clientes, concorrentes e companhia - e, de outro, na implementação dos quatro "Ps" produto, preço, "local" e promoção.
Essa abordagem aplica-se em geral a mercados em que o preço é definido levando-se em conta um segmento específico. No entanto, para muitos mercados importantes (sistemas de pagamentos el etrônicos como cartões de débito e crédito, videogames, sistemas operacionais, portais de Internet e quase todo tipo de mídia, como rádio, TV e 
jornais) está surgindo uma nova abordagem econômica na qual o foco deixa de ser simplesmente o nível de preço para se focar na estrutura de preços, ou seja, qual segmento do mercado deve pagar mais e qual deve ser subsidiado. Essa abordagem leva em conta que, em todos os exemplos citados, o produto ou serviço, para existir, precisa ser comprado (ou visto, usado, ouvido) por dois ou mais segmentos simultaneamente. Veja um exemplo. Uma revista (ou canal de TV, ou rádio) que não atraísse, em quantidades compatíveis, leitores (ouvintes, espectadores) e anunciantes provavelmente não duraria muito tempo. É comum que as editoras obtenham a maior parte de sua receita somente dos anunciantes, enquanto seus leitores pagam um preço abaixo do custo.

Mercado de dois lados. Na literatura acadêmica de economia, tais mercados são chamados, de maneira um tanto infeliz, de "mercados de dois lados" (uma expressão mais descritiva seria "mercados interdependentes"), ou, no original inglês, two-sided markets. Devido à vital importância desses mercados para todas as economias modernas, esse é um dos temas centrais no debate econômico geral e, especialmente, de defesa da concorrência em todo o mundo. cia de inúmeros portadores de cartões, com disposição de efetuar seus pagamentos, estimula o credenciamento de lojistas; por sua vez, a existência de lojistas, dispostos a aceitar os cartões, estimula sua demanda. Logo, essas empresas precisam distribuir grande quantidade de plástico para induzir os consumidores a usar o cartão; o que só vai ser possível se uma quantidade também grande de lojistas for convencida a aceitá-lo.

Essência econômi ca. Q uer esteja em foco uma revista, com seus assinantes e anunciantes, uma empresa de dinheiro plástico, com seus portadores de cartão e seus lojistas associados, pode-se identificar algumas características comuns a todos os mercados de dois lados. A seguir destacamos três dessas características que julgamos essenciais nesse tipo de mercado.

Em primeiro lugar, devem existir categorias diferentes de consumidores que demandem produtos relacionados. Por exemplo, a Volkswagen pode vender tanto caminhões como carros. Talvez seja mais barato fazer um se a empresa faz também o outro, mas a empresa pode existir eprosperar vendendo somente caminhões ou carros. No mercado de dois lados, a transação ou o "negócio" só se real iza com a ação dos clientes em ambos os lados da transação. O utro exemplo: no mercado de videogames, é necessário haver jogadores e criadores de jogos; em transações com cartões de pagamentos, é preciso que aconteça 0 encontro do portador de cartão com o lojista credenciado.

Em segundo lugar, o valor do serviço para os consumidores de um lado do mercado depende das características e da quantidade de consumidores do outro lado do mercado.

Um tipo de mercado de dois lados em especial tem atraído intensa atenção das autoridades de defesa da concorrência em todo o mundo: o mercado de pagamentos eletrônicos. Esse mercado é globalmente dominado por duas grandes associações (Visa e MasterCard) e, com a crescente importância de um sistema de pagamentos saudável para qualquer economia, tais empresas estão sendo duramente questionadas.

As empresas de cartões de pagamentos, de crédito ou de débito, são um mercado de dois lados típico: a existên-
Quanto mais aceito é um cartão de pagamento, maiores serão os benefícios proporcionados para o consumidor que o utiliza e para o lojista que o aceita. O s economistas dão a esse processo o nome de "externalidade de rede". Por exemplo, para um anunciante em TV, o valor de um slot de tempo durante a novela do horário nobre vale mais do que durante a sessão de filmes da tarde, devido ao número muito maior de telespectadores, assim como, provavelmente, também devido a um poder de compra mais elevado do espectador da noite em relação ao da tarde. 
E, em terceiro lugar, as economias de rede cruzadas (ao contrário de uma rede como o tel efone, em que a rede se torna mais val iosa quanto mais usuários do mesmo tipo houver, no caso em questão o produto ou serviço se torna mais valioso quanto mais usuários do outro tipo existir. Um portador de cartão quer seu cartão aceito em muitas lojas, um jogador quer muitos jogos e daí por diante), relacionadas com a existência de mais participantes em cada lado do mercado, não podem ocorrer sem a presença de um intermediário. Como exemplo dessa característica, um indivíduo pode tentar vender seu carro recorrendo ao chamado "boca-a-boca" no escritório. Pode até ser que consiga vendê-lo, mas certamente será mais efi ciente se colocar um anúncio nos classificados de um grande jornal. Este terceiro será o provedor da plataforma para a realização do "negócio". Ele pode ser uma bolsa de negócios, um fabricante de consoles de jogos el etrônicos, um mercado de capitais organizado ou uma rede de cartões de pagamentos - MasterCard e Visa -, por exemplo.

Maximi zação do lucro. Os princípios de maximização do lucro em teoria econômica são relativamentesimples. As firmas maximizam a diferença entre receita e custo de produção, estabelecendo preços de maneira que a receita da venda da última unidade seja igual ao custo de produzir esta última unidade.

Mas o preço que maximiza lucros em um mercado de dois lados não é definido tão facilmente, visto que as demandas pelos produtos relacionados devem ser consideradas simultaneamente. A mudança do preço da assinatura de uma revista é algo que, com certeza, alterará o número de leitores e talvez dados demográficos e sociais do corpo de leitores, afetando, em conseqüência, a demanda por espaço de publicidade. De fato, considerar a demanda e o custo em apenas um lado de um mercado de dois lados não é suficiente para determinar o preço que maximiza o lucro.

Segue, conforme adiantamos no início do artigo, que em mercados de dois lados, al ém do nível de preços, é preciso considerar também a estrutura de preços, ou então o modo como o preço total será dividido entre os diferentes segmentos do mercado. No mercado de cartões de crédito e débito, por exemplo, a estrutura atual de preços consiste em o varejista pagar a maior parte da receita das empresas no setor. 0 portador do cartão é subsidiado. Em alguns casos, como ocorre com o American Express, o varejo responde por, aproximadamente, $82 \%$ da receita.

A té pode fazer sentido cobrar um preço negativo de um dos lados do mercado. A Microsoft, para citar um caso conhecido, gasta milhões de dólares anualmente fornecendo serviços e ferramentas, abaixo do custo, para designers de software de maneira a encorajá-los a desenvolver aplicações para Windows. 0 retorno vem indiretamente por meio da venda do Windows para os usuários finais, atraídos pela grande quantidade de aplicações.

U m fator que determina como os custos são distribuídos entre os dois lados éo grau de dependência dos usuários de um particular intermediário. Os usuários de sistemas operacionais, como o Windows ou o Linux, e consoles de videogames como o PlayStation (Sony) ou X Box (Microsoft), por exemplo, são relutantes em mudar de platafor-

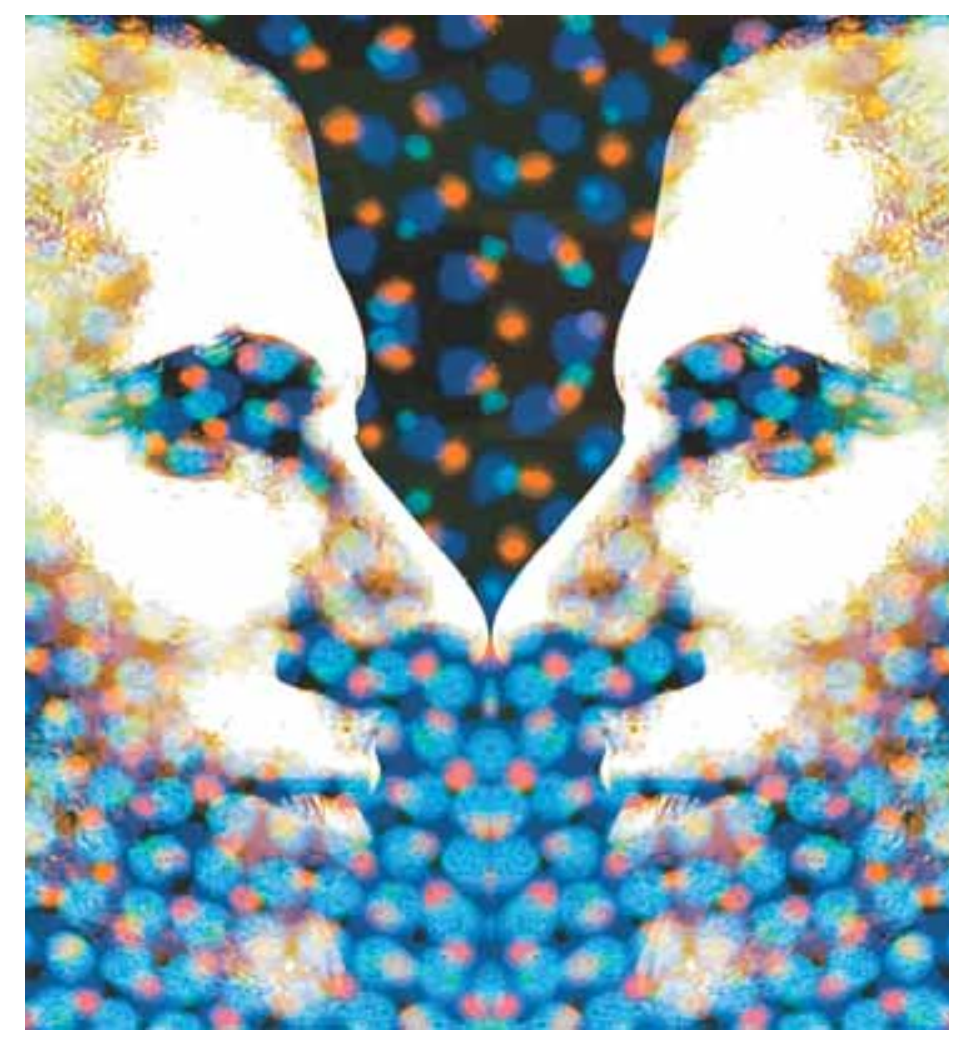


ma. Por seu lado, os desenvolvedores de software e games criam seus produtos para várias plataformas. Já com os portadores de cartão de pagamento, em contraste, diversas pessoas carregam mais de um cartão.

Exatamente de que forma esse multihome (termo ainda sem equivalente em português que significa uso de mais de um cartão de crédito, de mais de uma plataforma de videogame ou mais de um sistema operacional, por exemplo) afeta a estrutura de preços é um assunto complexo. Esse é um tema de ponta em pesquisa acadêmica. Um resultado empírico obtido no caso de cartões é que multihome parece não ser muito importante nesse mercado, uma vez que, apesar da maioria dos portadores carregarem cartões Visa e M asterCard, apenas um deles é efetivamente usado. gócios B2B. O u seja, os ganhos de escala e das externalidades positivas de rede trazem maiores benefícios para os consumidores e para a sociedade do que a competição entre várias organizações menores.

Por último, embora importante, por mais competitivos que sejam os dois lados, é improvável que preços e custos andem com passos iguais nos dois lados desses mercados. Já que é comum um dos lados bancar a maior parte dos custos, é provável que os preços cobrados de um dos lados do mercado sejam muito maiores do que os custos correspondentes. 0 lado menos sensível a preço provavelmente pagará mais para permanecer na rede, e esse excesso será utilizado para subsidiar o outro lado, mais sensível às al terações de preços, a permanecer na rede.

Todos esses fatos implicam um

\section{O modelo tradicional de precificação em}

\section{economia forneceu diretrizes importantes}

\section{para as economias capitalistas. Suas fraquezas}

\section{na análise dos mercados contemporâneos,}

\section{porém, são cada vez mais aparentes.}

grande desafio para as atividades de defesa da concorrência, dado que a competição nos mercados de dois lados segue uma lógica sui generis, cuja prática de mercado pode ser confundida com comportamentos anticompetitivos ou de monopólio. A distinção entre esses casos e os de abuso de poder de mercado é uma linha muito tê-

Defesa da concorrência. Por diversos motivos, empresas operando em mercados de dois lados são bastante propensas a atrair atenção das autoridades de defesa da concorrência. Mercados de dois lados exibem efeitos de rede, que aumentam o tamanho a partir do qual uma empresa opera na escala eficiente. Quanto mais pessoas compram no E-Bay, mais valioso fica o site para compradores e vendedores. Por isso, não deve causar surpresa 0 fato de que $85 \%$ de todo o tráfego em sites de leilão ocorra no E-Bay. Isso, evidentemente, atrai a atenção das autoridades de defesa da concorrência.

Na maioria dos mercados com economias de rede, não há espaço para duas ou mais empresas - por exemplo, Microsoft, Sony e Nintendo; Visa e MasterCard; Bolsas de Val ores etc. Em al guns mercados, a presença de uma única empresa não prejudica a eficiência econômica - é o caso, por exemplo, da Bolsa de Valores e da bolsa de ne- nue cuja demarcação muda constantemente.

Mudança de hábito. Fechando este artigo que pretendeu esboçar a essência dos problemas de economia empresarial e de regulamentação dos mercados de dois lados, pode-se lembrar que modelos econômicos não são melhores que as suposições subjacentes a eles. 0 modelopadrão para mercados de um lado forneceu diretrizes importantes para as economias capitalistas. Suas fraquezas na análise dos mercad os contemporâneos, porém, são cada vez mais aparentes.

$\mathrm{N}$ a verdade, essa é uma péssima notícia para executivos e reguladores que admitem que o mundo está mudando mas ainda não dispõem de instrumentos de navegação ad equados às águas traiçoeiras que estão se formando. No mundo atual marcado pela interdependência entre mercados navegar é necessário, mas a compreensão de 


\section{O Mercado Brasilei ro de Cartões}

Os cartões de pagamento no Brasil tiveram um crescimento rápido. Os pagamentos com cartões cresceram em média $27 \%$ ao ano no período de 1999 a 2004 e correspondem a mais de $36 \%$ da quantidade total dos pagamentos que não são efetuados em papel-moeda. 0 volume financeiro transacionado passou de cerca de 40 bilhões de reais em 1999 para mais de 135 bilhões de reais em 2004.

Para se entender os números a seguir é importante lembrar que a cadeia de valor do sistema de cartões de pagamentos constitui-se, de maneira simplificada, em emissores (os bancos que oferecem cartões aos clientes), adquirentes (empresas que atendem o varejo e são responsáveis pelas redes de comunicação e os terminais de pagamento) e processadores (mantêm grandes computadores que fazem os débitos e créditos, além de oferecerem outros serviços como emissão de faturas) e, finalmente, as bandeiras (Visa, MasterCard, American Express, Hipercard e Diners).

0 mercado de cartões de pagamentos é dominado pelas principais bandeiras internacionais. Em 2004, aVisa detinha 50,8\% do mercado, seguida pela MasterCard com 45,9\%, American Express, 2,2 \% , e Diners, 1,1\% . No mercado de emissão de cartões, existe grande concorrência entre os diversos emissores (bancos). Em 2004, os cinco maiores emissores respondiam por $60 \%$ do mercado. Atualmente, existem 33 emissoresVisa, 74 emissores MasterCard e 5 emissores Diners atuando no mercado.

0 mercado de adquirentes brasileiro é, comparado com o externo, um oligopólio: duas empresas controlam mais de $90 \%$ do mercado. A Redecard atua no credenciamento de estabelecimentos para aceitação de MasterCard e Dinners e aVisanet atua no credenciamento para aceitação do sistema Visa. Em 2004, 0 maior adquirente em volume financeiro liquidado era aVisanet, com $58 \%$ do mercado, seguida pela Redecard com $37 \%$ e American Express, rede fechada, com $5 \%$.

A estrutura, aparentemente pouco competitiva, do mercado nacional de adquirentes tem possibilitado a manutenção de práticas "pouco ortodoxas" pelos padrões internacionais. A principal delas, que só existe no Brasil, é o prazo de 28 dias para pagamento dos recebíveis de cartões de crédito (cartões de débito seguem a norma internacional de três dias úteis). Dado 0 nível de taxa de juros no Brasil, esses 28 dias adicionais elevam o desconto que é cobrado do varejista (de $1 \%$ a $7 \%$ do valor bruto para crédito) em aproximadamente $2 \%$. Essa peculiaridade possibilita um negócio lucrativo e de baixo risco (já que o risco de crédito é o banco emissor do cartão) no qual as empresas adquirentes "antecipam" a receita aos varejistas, cobrando por isso taxas que variam de $2 \%$ a $3 \%$. Essa "antecipação de recebíveis" é uma fonte importante de receita na Redecard. No caso da Visanet o negócio é feito pelos bancos sócios da empresa.

Outra característica particular no mercado brasileiro é o aluguel da infra-estrutura de acesso por parte de cada rede individualmente, ou seja, para a aceitação de cartões, os lojistas são obrigados a pagar um aluguel pelos terminais de POS acrescidos de uma taxa de conexão com cada rede em separado. No exterior, geralmente, 0 varejista compra a máquina de POS no mercado competitivo e não necessita se conectar às várias infra- estruturas de rede. Essa ausência de interoperabilidade de terminais POS entre as grandes redes de cartões (Visa, MasterCard e American Express) não se explica por barreiras meramente tecnológicas, e o Banco Central tem insistido para que as redes compartilhem seus terminais no ponto-de-venda. conceitos fundamentais como concorrência saudável ainda está longe de ser precisa.
Marcelo C. R. Deschamps D'Alvarenga

Assessor Sênior do Departamento de Operações Bancárias (DEBAN) e de Sistema de Pagamentos do BACEN*

E-mail: marcelo.deschamps@bcb.gov.br

José Augusto G. da Silveira

Prof. do Departamento de Administração da FEA-USP

E-mail: jags@usp.br
Ricardo F. Paixão

Pesquisador e Prof. de Educação Executiva do Centro deEstudos Avançados em M eios de Pagamento (CEAMP) da USP

E-mail: rfp@usp.br

${ }^{*}$ ) as opiniões expressas neste trabalho são exclusivamente do autor e não refletem a visão do Banco Central do Brasil 